\title{
Research of the Breakdown Rock Mass Parameters Under Conditions of the Transportless Mining System
}

\author{
Valery Kolesnikov \\ Mining Institute \\ T.F. Gorbachev Kuzbass State \\ Technical University \\ Kemerovo, Russian Federation \\ kvf.rmpio@kuzstu.ru \\ Alexander Katsubin \\ Head Office \\ OJSC «SUEK-Kuzbass» \\ Leninsk-Kuznetsky, Russian Federation \\ katsubinav@suek.ru
}

\author{
Vctor Martyanov \\ Mining Institute \\ T.F. Gorbachev Kuzbass State \\ Technical University \\ Kemerovo, Russian Federation \\ martvic2005@yandex.ru
}

\author{
Eugene Makridin \\ Head Office \\ OJSC «SUEK-Kuzbass» \\ Leninsk-Kuznetsky, Russian Federation \\ makridinev@suek.ru
}

\begin{abstract}
Intensive mining in the Kuzbass region (Russia) and high environmental impact imply the development of both energy saving and environmental saving technologies. One of the directions is the decrease in the use of heavy vehicles via the non-transport flat seams mining. At the same time to increase the efficiency of the draglines operation, it is necessary to have information about the internal structure of the breakdown rock mass formed by the explosion of high $(H \geqslant 30$ m) ledges. The drilling and blasting parameters used (especially the slope of the boreholes) give a fundamentally different structure of breakdown rock mass: with vertical boreholes, a more homogeneous structure of breakdown is observed than with the use of inclined ones. At the same time, when using inclined boreholes, a more suitable breakdown profile is formed to accommodate the draglines.
\end{abstract}

Keywords-transportless mining system, blast, dragline, breakdown rock mass

\section{INTRODUCTION}

Today open pit mining is a soaring sector of coal industry around the world, due to its economic [1] and safety advantages [2, 3], and lower risks of investments $[4,5]$.

One of the very positive features of blasting with the use of deep (up to 30 meters) inclined boreholes with a nontransport mining system is the possibility of using explosion energy to move a certain part of the overburden from the blasted ledge into the worked-out space reducing the volume of excavator operations. It is equivalent to increasing the productivity of excavators [6-10].

In the regular explosions using vertical and inclined boreholes depths up to $30 \mathrm{~m}$, some of the rock is also moved into the worked-out open pit mine and partly into a permanent dump. In this case, the volume of the discharged rock is $5-8 \%$ with vertical boreholes and $22-23 \%$ with inclined ones depths of up to $30 \mathrm{~m}$ with tamping of $14-15 \mathrm{~m}$.

The analysis of the obtained data of the discharge rock mass volumes indicates the determination of the technical and economic indicators of drilling and blasting operations and the assessment of the non-transport mining system should be carried out with the effect of the discharge rock mass into the worked-out open pit space.

\section{MATERIALS AND METHODS}

In the Kuzbass, some researches were made of the influence of the boreholes inclination, the specific consumption of explosives, the height of the ledge, the height of its face part and the width of the stope on the efficiency of drilling, blasting and excavating operations. Also, the geometry of the breakdown mass surface, the distribution of rock in the worked-out open pit space, the shattering coefficient of the rock in the blasted rock mass were studied. The obtained data allow to predict the configuration of the breakdown profile during blasts with the discharge of rocks into the worked-out space [11-18].

It was found the geometry of the breakdown surface affects the installation of the dragline on the blasted rock mass and determines the volume of the intermediate bulk of rocks.

Fig. 1 shows surveys of the breakdown profiles obtained by blasting of the inclined deep boreholes. From the surveys the surface of the breakdown in the profile has a complex curvilinear shape.

For a more detailed study of the explosion of deep inclined boreholes and the formation of a breakdown rock mass, a high-speed video of the explosion was analyzed with the following parameters of the blasted block: the total height of the pit edge is $64 \mathrm{~m}$; the height of the exploded ledge is 44 $\mathrm{m}$. 


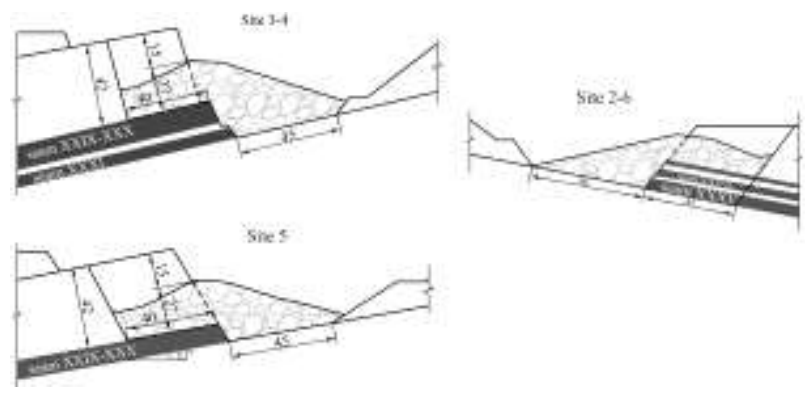

Fig. 1. Fig.1. The breakdown profiles obtained by blasting of the inclined deep boreholes (the measures in meters).

The parameters of drilling and blasting operations: the depth of boreholes is $44 \mathrm{~m}$; the inclination of the boreholes is $80^{\circ}$ (to horizontal plane); the tamping length is $8 \mathrm{~m}$; diameter of boreholes is $0.19 \mathrm{~m}$; the length of the blasting charge is $38.8 \mathrm{~m}$; the summary mass of the blasting charge is $1080 \mathrm{~kg}$; specific consumption of explosives is $400-600 \mathrm{~g} / \mathrm{m} 3$; number of rows of blastholes is 6 .

The coefficient of overexposure in the profile of the technological scheme is from 0.5 to 0.9 , depending on the method of development of the suite. The general coefficient of overexposure, which takes into account the creation of trails for lifting and lowering the dragline to the dumping stages, is 1.7-2.3. The tiers of the internal dump may be two or three, depending on the height of the rock formation being developed. At present, the height of the internal dumps is 60$70 \mathrm{~m}$.

The overburden from the transport ledges in all sections is transported to the surface of the internal dump, where it is stored in two or three tiers. On the internal dumps it is allowed to store the ground mix of bedrock and loose sediments.

\section{RESULTS AND DISCUSSION}

The following results were obtained by the high-speed image acquisition:

0.025 seconds into initiation of the first-line blasting charges, the detonation products from the borehole ejected to the height $\mathrm{H}(\mathrm{I})=10 \mathrm{~m}$.

$0.050 \mathrm{sec}$ into initiation of the first-line blasting charges $\mathrm{H}(\mathrm{I})=10 \mathrm{~m}$, the detonation products from the second-row boreholes were ejected.

$0.050 \mathrm{sec}$ into initiation of the first-line blasting charges there was a detonation of the third row of boreholes, and $\mathrm{H}(\mathrm{I})$ $=28 \mathrm{~m}$. There was a shift on $4 \mathrm{~m}$ of the top of slope, limited by the first row of boreholes, with a turn along the radius equal to the height of the slope of the ledge with the location of the center of rotation in the upper edge of the coal seam (it is the bottom of the borehole). The lower part of the ledge remains fixed, as shown on Fig.2.

$0.200 \mathrm{sec}$ into initiation of the first-line blasting charges there was a detonation of the fith row of boreholes and $\mathrm{H}(\mathrm{I})$ $=40 \mathrm{~m}$. There was a shift on $6 \mathrm{~m}$ of the top of slope.

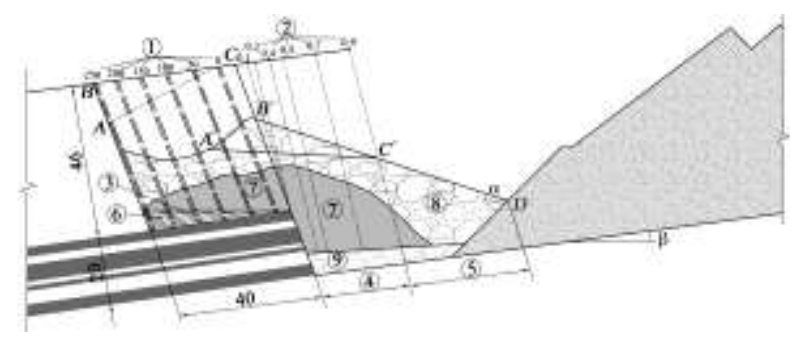

Fig. 3. The scheme for the formation of the breakdown of the rock mass 1 - intervals of the blasting deceleration between the rows of boreholes, in milliseconds; 2 - time of shift, in seconds; 3 - line of detachment and displacement of the rock massif; 4 - part of the breakdown formed by the displacement and deposition of the rock massif; 5 - part of the breakdown, formed by the displacement and collapse of rock mass; 6 - broken not shifted massif; 7 - shifted and fragmented massif with an disturbed structure; 8 - explosion-displaced massif; 9 - the rock mass remaining from the previous stope; $\mathrm{ABC}$ and $\mathrm{A}^{\prime} \mathrm{B}^{\prime} \mathrm{C}^{\prime}$ - rock triangles, respectively in situ and displaced by an explosion; $\alpha=15-20^{\circ}-$ the angle of the slope of the breakdown; $\beta=12^{\circ}$ - the inclination of coal beds.

$0.300 \mathrm{sec}$ into initiation of the first-line blasting charges there was a detonation of the last row of boreholes and H(I) $=50 \mathrm{~m}$. There was a shift on $10 \mathrm{~m}$ of the top of slope and on $4 \mathrm{~m}$ of the toe of blasting slope. The rock prism shifted beyond the top of slope basset downward along the coal-rock slope onto the bedrock.

$0.400 \mathrm{sec}$ into initiation of the first-line blasting charges there was a shift of the blasted massif along its entire height and width to the worked-out space by $14 \mathrm{~m}$.

$0.500 \mathrm{sec}$ into initiation of the first-line blasting charges the scattering of pieces of rock began and the ejection of the explosion products towards the worked-out space, the shift of the ledge increased to $18 \mathrm{~m}$.

$0.700 \mathrm{sec}$ into initiation of the first-line blasting charges the shift of the ledge increased to $27 \mathrm{~m}$.

$0.900 \mathrm{sec}$ into initiation of the first-line blasting charges the shift of the ledge increased to $37 \mathrm{~m}$.

The upper part of the breakdown (Fig.2, line B'-D) located in the worked-out space is actually a straight line directed at an angle $\alpha=15-20^{\circ}$ from the slope of the inner dumps to the intersection with the former slope of the exploded ledge. Point B' is the top of the breakdown. Further, the line of the breakdown takes the form of a curved concave surface. The structure of the breakdown through the displacement of inter-row blocks to the worked-out space in zone 7 and triangle $\mathrm{A}^{\prime}-\mathrm{B}^{\prime}-\mathrm{C}^{\prime}$ (see Fig. 2) remains the same as in the ledge, but only the disruption of continuity and volume increase are appeared. The presence of such explosionshifted massifs with preservation of the structure is well traced during excavation of the breakdown. The triangle A'$\mathrm{B}^{\prime}-\mathrm{C}^{\prime}$ represents the shifted part of the $\mathrm{ABC}$ tamped layer, since the stratification structure of the rock is the same as that in the upper part of the ledge (legs A-B and A'-B').

\section{CONCLUSION}

Analysis of high-speed image acquisition of the explosion and the study of profiles of the shape of the breakdowns of the exploded rock massifs using deep and inclined boreholes, revealed a significant difference in the mechanism of the impact of the explosion on the rock massifs being destroyed in comparison with the explosions of vertical boreholes. With vertical ones failure occurs in the ascending direction in a crater-shaped manner with some 
swelling toward the ledge slope. This study shows that with inclined boreholes of the blasted rock mass are shifted toward the worked-out space at a speed of $35-40 \mathrm{~m} / \mathrm{sec}$ with a discharge factor of $42 \%$.

Observations and analysis of the resulting surfaces of breakdowns at deep inclined boreholes have shown that the shape of the breakdown surface is very suitable both for placing draglines on it and for the conditions of its development. The explosion produces a "crest of breakdown" is in fact an intermediate pile favor the placement of the dragline in the bulk. As a result, the amount of the bedding course and the secondary excavation is negligible.

Convenient conditions for the development of the breakdowns should also include the presence of rock "kick out" (ejection) from the pit edge as a result of the increased blasting charge of the last row of boreholes. The presence of a notch contributes to better filling of the excavator bucket and provides maximum productivity of draglines with bottom scooping.

\section{REFERENCES}

[1] M. Cehlar and I. Cehlarova, "Cut winnings methods of an open-pit mine development," Acta Montanistica Slovaca, vol. 12 (3), pp. 174-181, 2007.

[2] A.B. Efremenkov, A.A. Khoreshok, S.A. Zhironkin, and A.V. Myaskov, "Coal Mining Machinery Development As An Ecological Factor Of Progressive Technologies Implementation," IOP Conference Series-Earth and Environmental Science, vol. 50, p. 012009, 2017.

[3] M.A. Tyulenev, Yu.V. Lesin, S.V. Vik, and S.A. Zhironkin, "Methodological Bases of Advanced Geo-ecological Problems Resolving in Neo-industrial Clusters," Proceedings of the 8th Russian-Chinese Symposium Coal in the 21st Century: Mining, Processing, Safety, vol. 92, pp. 333-336, 2016.

[4] M. Cehlar, K. Teplicka, and S. Szabo, "Possibility of new mining project extracting in conditions of crisis," Acta Montanistica Slovaca, vol. 14 (4), pp. 314-322, 2009.

[5] M. Cehlar, I. Cehlarova, and J. Szaboova, "Economic variables of the mineral project like the factors affecting cash flow,” Acta Montanistica Slovaca, vol. 12 (3), pp. 133-139, 2007

[6] M. Tyulenev, O. Litvin, M. Cehlar, S. Zhironkin, and M. Gasanov, "Estimation of Hydraulic Backhoes Productivity for Overburden Removing at Kuzbass Open Pits," Acta Montanistica Slovaca, vol. 22 (3), pp. 296-302, 2017.

[7] O. Litvin, M. Tyulenev, S. Zhironkin, and S. Prokopenko, "Methodology of coal losses calculation at open pit mining for complex geological conditions - review," Acta Montanistica Slovaca, vol. 22 (2), pp. 146-152, 2017.

[8] M.A. Tyulenev, S.A. Zhironkin, O.I. Litvin, E.A. Tyuleneva, O.V. Zhironkina, and S.O. Markov, "Safe and Productive Application of Hydraulic Backhoes in Coal-Bearing Areas of Complex Structured Deposits," Geotech. and Geolog. Eng., vol. 35(5), pp. 2065-2077, 2017.

[9] M.A. Tyulenev, A.A. Khoreshok, E.A. Garina, S.N. Danilov, and S.A. Zhironkin, "Adaptive Technology of Using Backhoes for Full Coal Extraction," Proceedings of the 8th Russian-Chinese Symposium Coal in the 21st Century: Mining, Processing, Safety, vol. 92, pp. 111-115, 2016.
[10] Aksenov V.V. Justification of value of the loads applied to the face for simulation of tools and rocks interaction / V.V. Aksenov, V.Yu. Sadovets, D.A. Pashkov // Journal of Mining and Geotechnical Engineering. - 2018. - №1. - C. 11-18. DOI: 10.26730/2618-7434-2018-1-11-18

[11] T. Gvozdkova, M. Tyulenev, S. Zhironkin, V.A. Trifonov, and Y.M. Osipov, "Rational Use of Land Resource During the Implementation of Transportless System of Coal Strata Surface Mining," IOP Conference Series-Earth and Environmental Science, vol. 50, p. 012010, 2017.

[12] Ermakova I.A. Setting of flow parameters during release of ore in caving systems / I.A. Ermakova // Journal of Mining and Geotechnical Engineering. - 2018. - №1. - pp. 4-10. DOI: 10.26730/2618-7434-2018-1-04-10

[13] M.A. Tyulenev, T.N. Gvozdkova, S.A. Zhironkin, and E.A. Garina, "Justification of Open Pit Mining Technology for Flat Coal Strata Processing in Relation to the Stratigraphic Positioning Rate," Geotech. and Geolog. Eng., vol. 35(1), pp. 203-212, 2017.

[14] Misnikov O.S. The foggy future of the peat industry in Russia / O.S. Misnikov, V.V. Panov // Journal of Mining and Geotechnical Engineering. - 2018. - №1. - pp. 42-55. DOI: $10.26730 / 2618-7434-2018-1-42-55$

[15] Markov S.O. Georadar research of the block structure for drilling and blasting operations on Zarechnyi open pit mine / S.O. Markov, M.A. Tyulenev, E.G. Kuzin // Journal of Mining and Geotechnical Engineering. - 2018. - №1. - pp. 5663. DOI: $10.26730 / 2618-7434-2018-1-56-63$

[16] V.A. Ermolaev, A.A. Sysoev, I.O. Litvin, and A.V. Selyukov, "The degree of availability of mineral resources for mining," Bulletin KuzSTU, №1, pp. 26-30, 2017.

[17] L.V. Kuznetsova and B.A. Anfyorov, "Selective mining of mineral resources: experience, systematization and prospects of application at complex development of coal deposits," Bulletin KuzSTU, №1, pp. 75-83, 2018. DOI: 10.26730/19994125-2018-1-75-83

[18] G.D. Buyalich, M.K. Husnutdinov, and A.A. Bakanov, "Assessment of forms of cross-section of blasting bag for destruction of rock,” Bulletin KuzSTU, №1, pp. 53-58, 2017. 